BULLETIN Bulletin hispanique

HISPANIQUE Université Michel de Montaigne Bordeaux

120-1 | 2018

Varia

\title{
Súplica del perdón divino en Las lágrimas de David de Felipe Godínez
}

Prière du pardon divin dans "Les larmes de David" de Felipe Godínez

Prayer for the divine forgiveness in 'David's Tears' by Felipe Godinez

\section{Miquel Beltrán}

\section{(Q) OpenEdition}

\section{Journals}

\section{Edición electrónica}

URL: https://journals.openedition.org/bulletinhispanique/5722

DOI: 10.4000/bulletinhispanique.5722

ISSN: $1775-3821$

Editor

Presses universitaires de Bordeaux

Edición impresa

Fecha de publicación: 30 junio 2018

Paginación: 207-222

ISBN: 979-10-300-0298-0

ISSN: 0007-4640

\section{Referencia electrónica}

Miquel Beltrán, «Súplica del perdón divino en Las lágrimas de David de Felipe Godínez», Bulletin

hispanique [En línea], 120-1 | 2018, Publicado el 01 enero 2022, consultado el 07 enero 2022. URL:

http://journals.openedition.org/bulletinhispanique/5722 ; DOI: https://doi.org/10.4000/

bulletinhispanique.5722 


\title{
Súplica del perdón divino en Las lágrimas de David de Felipe Godínez
}

\author{
Miquel BeLtrán \\ Universidad de las Islas Baleares
}

Dans sa comédie biblique intitulée Las lágrimas de David, probablement écrite en 1635, Felipe Godínez offre une conception du pardon divin conforme à celle de l'Ancien Testament. Notre propos est d'analyser les traits de cette conception à travers les notions clés de hesed et berit.

Mots clés: Dieu, Godínez, Comédie biblique, David, repentir, pardon.

En su comedia Las lágrimas de David, escrita con probabilidad en 1635, Godínez expone una concepción del perdón divino acorde con la que hallamos en el Antiguo Testamento. Damos cuenta aquí de cuáles son las peculiaridades de aquella concepción, a través del examen de ciertos conceptos como hesed y berit.

Palabras clave: Dios, Godínez, Comedia, David, arrepentimiento, perdón.

In his Comedia 'Las lágrimas de David', probably written in 1635, Godínez expresses a conception of divine forgiveness similar to that found in the Jewish tradition. Here, we will give an account of some key concepts for the understanding of divine forgiveness in the Old Testament, like hesed and berit.

Keywords: God, Godínez, King David, Repentance, Forgiveness. 
E

n su trabajo sobre la imagen del judío en la comedia, Herskovits (2005: 155-158) seńala que la importancia otorgada a David, por parte de los autores en la península escribieron obras teatrales en torno a personajes del Antiguo Testamento, puede probarse por el hecho de que hayan perdurado cinco textos capitales cuya trama se urde en torno a la figura del monarca ${ }^{1}$. Esta predilección se concreta sobre la exposición del carácter moral que refleja el rey al llevar a cabo sus acciones en las distintas obras, harto diverso en unas y otras, y que ha propiciado también las subsiguientes -y a veces antagónicasinterpretaciones que se concitan entre los estudiosos con respecto a las virtudes y debilidades que caracterizan a David. En ciertas obras es perceptible su condición casi de santidad, y la prefiguración de Cristo que él personifica, enfatizándose asimismo el carácter anticipatorio de su grandeza con respecto a la de aquel. El amor y la capacidad de misericordia del que el rey hace gala en Los cabellos de Absalón, por ejemplo, se contempla por algunos como más encomiables, incluso, que los que adornan al hijo de Dios, pues aquel es solo humano y, por tanto, su magnanimidad más meritoria (Edwards, 1973: 1-33) ${ }^{2}$. Resulta importante esta consideración por cuanto en una comedia como $E l$ arpa de David de Mira de Amescua ${ }^{3}$ nada podría hacer sospechar que el drama se desarrolla en el seno de la ética que caracteriza el Antiguo Testamento, y se vacía la narración de las peculiaridades que definen a esta. Y aunque Herskovits tiende a exagerar la descripción de David como un hombre vacilante y débil en la obra calderoniana, no yerra al destacar que el perdón incondicional que el rey se esfuerza por conceder a todos no parece nacer de la compasión, ni de la comprensión de las contradicciones en las que están sumidos aquellos a quienes se les otorga, sino que su clemencia se extiende como una suerte de obcecado hábito, como un celo no ponderado por mostrar una piedad que quiere hacer patente a toda costa. Señalaba Herskovits que en Los cabellos de Absalón "la práctica de la misericordia, en David, ignora....los requerimientos que un rey debe tener en cuenta, de justicia y prudencia, con las catastróficas consecuencias no solo para los perdonados, sino para el pueblo entero» ${ }^{4}$. No se ocupa el estudioso, sin embargo, como tampoco lo hizo Dixon $(1976)^{5}$, de

1. Se trata de El arpa de David de Antonio Mira de Amescua, La venganza de Tamar de Tirso de Molina, Los cabellos de Absalón de Pedro Calderón de la Barca, David perseguido y montes de Gelboé de Lope de Vega, y Las lágrimas de David de Felipe Godínez. Se halla también Trabajos de David y finezas de Micol, escrita por Cristóbal Lozano, autor obcecado por la figura de David, sobre la que escribió, además, las novelas David perseguido y alivio de lastimados, en tres partes (Madrid, 1652 a 1661) y El Rey penitente, David, una colección de discursos morales que sin su anuencia fue publicada como segunda parte del David perseguido. Otras comedias sabemos que se escribieron, como la que hoy consideramos perdida, cuya autoría es del propio Godínez, $\mathrm{La}$ harpa de David, sobre cuyo posible contenido se discurrirá en este artículo.

2. Cf. Gwynne Edwards, 1973, 1-33. Cf. también Edwards, 1978, como asimismo Albert E. Sloman, 1961.

3. Antonio Mira de Amescua, 2003.

4. Herskovits 2005, 147.

5. Cf. Victor F. Dixon, 1976. También Dixon, 1984. Cf. con respecto a la rebelión de Absalón tal como se narra en la Escritura Song Mi-Suzie Park, 2009 y sobre todo Keith Bodner, 
desvelar las causas de la honda piedad -en el sentido cristiano del término- que impregna el quehacer del rey, no ajena a la obligación moral que lleva a los católicos a considerar virtud conceder un perdón inmerecido, otorgado sin que se requiera el sincero arrepentimiento de aquel que lo recibe, que no precisa una contrapartida. Cabe que lo que esté en juego en la indiscriminada misericordia de David sea su propia salvación, y su clemencia para con los demás permitiría al rey obtener la redención pues este pretende, ante todo, limpiar la mácula de sus antiguos pecados ${ }^{6}$. Solo desde una perspectiva cristiana puede afirmarse de quien esto actúa que expresa una portentosa humanidad.

Nos interesa aquí probar, sin embargo, que la concepción del perdón divino que se halla en Las lágrimas de David, la obra que Felipe Godínez debió escribir en 1635, y así pues, en los mismos años en los que Calderón escribió la suya, evidencia que el autor de Moguer pretendió, ante todo, impregnar su obra del sentido que la asistencia divina y la precisa mecánica del correlato existente entre Dios y los hombres, en cuanto concierne al auxilio que el primero presta a sus criaturas, poseen en el hebraísmo veto-testamentario.

Cabe señalar, en este sentido, que la caracterización de David que lleva a cabo Godínez no hace del rey, a diferencia de lo que ocurre en Los cabellos de Absalón, un paradigma de virtud. Natán lo define como tirano ${ }^{7}-\mathrm{y}$ no hay que olvidar que él es el emisario de Dios, pues 'tiene palabra de Yavé, y en este sentido, no puede equivocarse (Janzen, 2012) - $^{8}$, y en la obra no se vacila en subrayar la crueldad de David para con Urías, y el cinismo con que hace que sea el soldado quien elija su propia desgracia, haciéndole responsable de la funesta decisión de volver a la contienda. Es constatable, en este sentido, que tal caracterización muestra una fidelidad manifiesta hacia los pasajes del Antiguo Testamento en los que se describen los episodios que componen la trama de la comedia.

Urías, en la obra, parece creerse sometido a un fatalismo que -según Herskovits piensa- se indica de continuo, mediante la introducción de conceptos tales como designio, ocasión, azar, o hado. En contraposición, dice el estudioso no hallar sino un solo lugar en el que Dios aparece, según su propia expresión, como "predestinador»".

No parece difícil poder dar cuenta, sin embargo, de que la recurrencia a aquellas nociones no desplaza, en la obra, el poder de Dios, que todo lo abarca -muy al contrario, en algunos casos lo afianza-; así, los designios que se refieren

2014 Cf. finalmente J. Hoftijzer, 1970.

6. Bien es cierto que la Torá establece que quien da el perdón activa su propio perdón en el cielo, conminando, pues, a su práctica, y que David, en Sal 121, 5 escribe que «Yavé es tu sombra a tu mano derecha», de modo que, así como nosotros nos movemos, Él se mueve con respecto a nosotros. Pero el perdón cristiano no puede ser explicado, se trata de una singularidad que hace surgir o emerger una decisión de concederlo sin condiciones.

7. III, v. 2759.

8. Cf. David Janzen, 2012.

9. Herskovits 2005, 157. 
son las meras intenciones de los interlocutores, al igual que el azar, en boca de Bersabé, es una inesperada respuesta, y en relación al hado, Joab se lamenta:

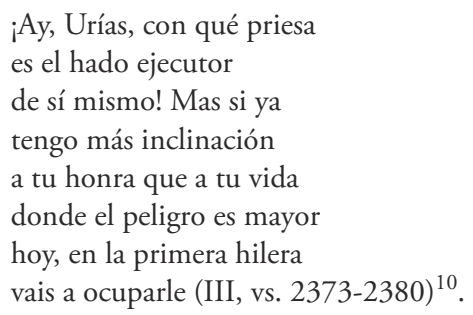

Un hado que concuerda en su capricho con la voluntad de David, sometida esta, a su vez, a la de Dios, como por lo demás no resulta inusual que se contemple entre los escritores españoles de su siglo y aun del anterior ${ }^{11}$.

Más allá de las líneas en las que Natán confirma que Dios es quien preordena todas las cosas, un pasaje crucial demuestra que todo depende, en la obra, del definitivo poder de Este. Tras preguntar David a Joab: «En fin, ¿queda vencido el filisteo?» (I, v. 201) Aquel le responde:
La asistencia de Dios, señor, ha sido la que, prestando fuerzas al hebreo, su ejército le ha roto y le ha vencido. Soberbio estaba por algún trofeo que había de tus armas conseguido, sin que su error infiel, que fuese, arguya, castigo nuestro, y no victoria suya. Pues, cuando en Dios tal vez algún pecado de su pueblo a venganza justa obliga, tiene Dios por azote levantado el brazo del infiel que le fatiga. Y así, el infiel que vence coronado, tal vez no vence, no, sino castiga; porque si Dios quien vence siempre ha sido, el que vence sin Dios nunca ha vencido (I, vs. 202-216).

Pues bien, Dios es el que vence, asistiendo a los soldados de Israel, del mismo modo en que, cuando los ejércitos contrarios alcanzan la victoria, son un mero instrumento a través del cual Él castiga a su pueblo. Así, por ejemplo, en el temor que confiesa Joab:

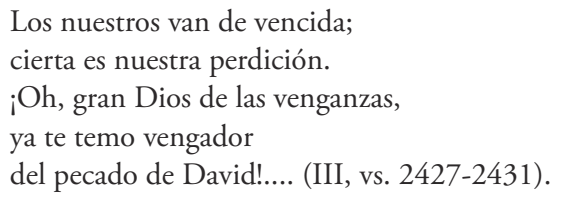

10. Citamos por la reciente edición de la obra, que debemos a Germán Vega García-Luengos. Se trata de Felipe Godínez, 2013.

11. Cf. Felipe Díaz Jimeno, 1987. 
Y así, dos interlocutores, Dios e Israel, y el primero como el único que en verdad actúa, pues es causa primera de lo que los humanos llevan a cabo.

Cabe señalar, sin embargo, que este poder de Dios, en tanto que agente ínsito en las criaturas que obran, autor de sus acciones más que ellas mismas, parece entrar en contradicción con -o ser puesto en entredicho por- otra consideración sobre Aquel, por mantener la cual Godínez fue acusado de judaizante en el auto de fe de 1624. En este, en efecto, se le denunció por afirmar

que Dios había dado en persona de Jacob palabra a los judíos de no irse del pueblo judaico hasta tanto lo redimiese, dando a entender que no había llegado el cumplimiento de esta palabra, y que con ella se había privado Dios de la libre potestad que tenía para no poder irse hasta que los redimiese, la cual proposición es herética, pues necesita a Dios que cumpla su palabra sin libertad, quitándole la voluntad ${ }^{12}$.

Godínez habría, de acuerdo con el auto de fe, menguado el poder de Dios al sostener que le es imposible faltar a las promesas hechas a los israelitas, lo que comporta limitar el poder divino, que se hallaría supeditado a la palabra dada.

Varias cosas son destacables con respecto a lo anterior. En primer lugar, que no se equivocaban quienes calificaron a Godínez de judaizante por mantener tal creencia, como queremos probar acto seguido. Sea dicho en passant, habrá que postular que, puesto que Godínez fue acusado como autor de la comedia La harpa de David y pese a que el episodio que tal título evoca remite a la relación de este con Saúl, ciertos de los temas podrían hallarse, más adelante, en Las lágrimas de David, pues, como veremos, la posibilidad del perdón divino se erige, en esta última obra, sobre el compromiso adquirido por Dios frente al monarca y a su descendencia a través de la alianza. Con todo, estamos de acuerdo con Vega García-Luengos cuando argumenta que se trataría, en cualquier caso, de dos obras distintas ${ }^{13}$.

12. Cf. Piedad Bolaños Donoso, 1991. Cf. también Germán Vega García-Luengos, 1986.

13. Leemos: «Es evidente en todas las obras conservadas del autor la total adecuación de sus denominaciones a los temas que en ellas se desarrollan. Sin embargo, nada hay en el texto de Las lágrimas de David que justifique el título dado en las relaciones del auto de fe. Es más, ni siquiera de manera tangencial se menciona el susodicho instrumento (se refiere al arpa); y eso que en una de las escenas finales David glosa con sus palabras de arrepentimiento fragmentos del salmo 50 de la Vulgata ( 51 en la Biblia hebrea) e intervienen como colofón los músicos. En cambio, el título que aparece asociado al texto en doce de las ediciones conocidas, Las lágrimas de David, sí que se ajusta, y además magistralmente por su ambivalencia, a la materia tratada, que no es otra que la del pecado con Bersabé y Urías, y el perdón del Rey Profeta. Las lágrimas juegan un papel decisivo en los dos momentos: las del amante rechazado consiguiendo lo que no habían logrado sus palabras, ablandar el corazón de la hasta entonces fiel esposa, y las del Rey arrepentido alcanzando el perdón de Dios por las culpas que siguieron a sus primeras lágrimas.

De ser exacto el título que se adjudica a la comedia en las relaciones, cabe más bien pensar que daría cabida, o trataría exclusivamente, episodios anteriores a los que dramatiza Las lágrimas de David. Desde el momento que Saúl hace llamar al arpista David para aliviar su mal de espíritu (1 Sam. 16) hasta cuando este, ya rey, encabeza alborozado el traslado del arca (2 Sam. 6), el arpa tiene un protagonismo que puede justificar el titulo; lo que no ocurre después, al menos desde la perspectiva de la fuente» (Vega García-Luengos, 1986: 108). 
Tal como señalábamos en otro trabajo ${ }^{14}$, la consideración bíblica de la asistencia divina se erige sobre la honda convicción de que el Dios de la alianza nunca muere: «¿No eres tú desde el principio, oh Yavé, Dios mío, Santo mío? No moriremos» (Ha 1:12). En el contexto escritutario Dios es, ante todo,

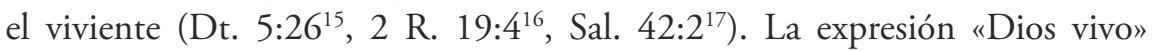
tiene distintos significados en los Salmos: «unas veces describe la exuberante vitalidad de Yavé frente a los dioses muertos que constituyen los ídolos; otras designa la asistencia divina a los piadosos que confían en Él, como en el capital texto de Sal 42:3 ${ }^{18}$, o en Sal 84: $3{ }^{19}$. La existencia es congénita a la insondable potencia a la que los hebreos llaman Yavé. Y su asistencia se materializa como una suerte de certidumbre en una protección profunda, ínsita en quien se encuentra en situación de peligro al tratar de llevar a cabo la misión que le ha sido encomendada, pues tiene el riesgo de fracasar en dicho menester. Una protección que, tal como decíamos en un estudio anterior, se concreta en la

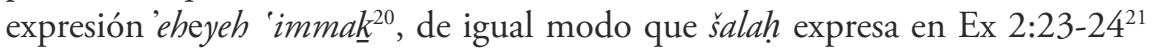
el auxilio que Dios presta a Moisés es perdurable, y que el profeta puede estar seguro de que se desplegará esta asistencia. Yavé otorga a Moisés la certeza que precisa al empeñarse en llevar a cabo lo que emprende, y la presencia divina hará posible, ante cada situación, su realización, como Gowan ha probado en un remarcable estudio ${ }^{22}$. Otro término, "memrá", establece "que la asistencia no alude al contenido o mensaje, sino al sujeto mismo, Dios, que al ser sustituido por memrá de Yavé adquiere la connotación de Dios en cuanto se comunica y actúa por la palabra. Su sentido equivaldría al de "hablante" $»^{23}$.

Las relaciones entre Dios e Israel, que garantizan la asistencia, están reguladas por la berit, una alianza, y la conducta que se espera de quienes se comprometen en la misma se califica de hésed. Esta alianza comporta que Dios, puesta la naturaleza inquebrantable de la promesa, no tiene la libertad de no cumplir su

14. Beltrán, 2015.

15. «Porque ¿qué es el hombre, para que oiga la voz del Dios viviente que habla de en medio del fuego, como nosotros la oímos, y aún viva?».

16. «Quizá oirá Yavé tu Dios todas las palabras del Rabsaces, a quien el rey de los asirios su señor ha enviado para blasfemar al Dios viviente».

17. «Mi alma tiene sed de Dios, del Dios vivo; ¿Cuándo vendré, y me presentaré delante de Dios?»

18. «Fueron mis lágrimas mi pan de día y de noche. Mientras me dicen todos los días: ¿Dónde está tu Dios?»

19. Beltrán, 2015, 129. El versículo reza: «Aun el gorrión halla casa, y la golondrina nido para sí, donde ponga sus polluelos, cerca de tus altares, oh Yavé de los ejércitos, Rey mío, y Dios mío».

20. «Estaré contigo».

21. «Aconteció que después de muchos días murió el rey de Egipto, y los hijos de Israel gemían a causa de la servidumbre, y clamaron; y subió a Dios el clamor de ellos con motivo de su servidumbre. Y oyó Dios el gemido de ellos, y se acordó de su pacto con Abraham, Isaac y Jacob».

22. Cf. Donald Gowan, 1994.

23. Beltrán, 2015, 130. Cf. sobre estos términos Enrique Sanz Giménez-Rico, 2002, y Domingo Muñoz León, 1977. Cf. asimismo Muñoz León, 1983. 
palabra, tal como Godínez pudo haber vindicado en el drama bíblico por el que fue acusado y que hoy damos por perdido, La harpa de David. El autor estaba firmemente convencido de que Dios actúa y está comprometido en el sentido que designa el hésed, como una suerte de lealtad erigida sobre el compromiso. Las estipulaciones de la concreción de la berit llevan íntimamente aparejada la predisposición a una mutua consideración, conducta exigida por la relación que se establece; sin la referencia al hésed, por ambas partes, sería impensable el mantenimiento de la berit ${ }^{24}$. Por ello en Israel aparece tenaz, arraigada, la convicción íntima de que la asistencia de Dios es algo que cabe esperar de Él, puesto que se funda sobre la relación de alianza.

En un primer momento podría estarse dispuesto a afirmar que las expresiones del sostén divino se hallan, en idéntico sentido, en la consideración de la bondad y misericordia divinas que plasman otras religiones. Pero las diferencias son notables. Sobre todo, la conexión del hésed de Yavé con el pacto, que da a la bondad divina un fundamento incomparablemente más firme. Israel podía hablar de un Dios cuya voluntad pretendía configurar toda la vida con una exclusividad celosa. Por ello la bondad auxiliadora de Dios posee un sentido interior que no se halla en los dioses babilonios de la naturaleza. Si estos pueblos tenían la magia y los conjuros como garantes de que no todo depende de la voluntad de la divinidad, la prohibición de la mántica y de la magia en Israel comportó una consideración cada vez más arraigada de que el hombre depende tan solo de la protección divina. El carácter propio de las expresiones israelitas sobre la bondad de Dios está constituido por la exclusividad, y por la relación con la historia.

Es esta perentoriedad con la que se vindica la condición de elegido del pueblo judío la que le importa a Godínez plasmar en sus obras, como Herskovits ha demostrado a propósito de las comedias escritas en torno a la figura de Ester ${ }^{25}$. Tal como Gluck señaló, el término 'hésed' es usado 245 veces en la Biblia hebrea. Una disposición íntima de Dios que le inclina a prestar asistencia, que se concreta en un auxilio opuesto al espontáneo y amoroso, al no merecido, pues Él está comprometido a prestarla solo en mutua consideración con cada miembro de la comunidad. Y estos deben mostrar, por su parte, una sincera contrición cada vez que una acción suya pone en peligro el pacto. Godínez apela a este compromiso en su obra, cuando David pronuncia su petición de perdón a Dios, en la que alega la transformación operada en su actuar mediante el arrepentimiento, obrada por él sobre sí mismo, en el primigenio sentido de la palabra 'tesúva', que connota, en el judaísmo, un auto-conocimiento por el que cabe encontrarse de nuevo con quien se era antes de acometer el acto del que se está arrepentido, un esclarecimiento de la propia condición, que es requsito previo para que Dios asista al hombre con el perdón, como se examina más adelante. Es capital destacar que este se da en respuesta al compromiso

24. Cf. Nelson Gluck, 2011. El original fue defendido como tesis doctoral en 1927. Cf. también Katharine Doob Sakenfeld, 1978.

25. Cf. también Ruth Fine, 2010. 
establecido por Dios con aquel que el rey vuelve a ser, tras su reflexión sobre las ignominiosas acciones por él mismo perpetradas. Se plasman, así, las condiciones sobre las que se establece, en el judaísmo, la relación entre el Dios que protege y el rey que sabe que Él ha comprometido su presencia ante el pueblo y, en particular, que ha forjado una predilección particular hacia David y su casa, tal como Yavé la manifiesta a través de Natán: «Ahora, pues, dirás así a mi siervo David: Así ha dicho Yavé de los ejércitos: Yo te tomé del redil, de detrás de las ovejas, para que fueses príncipe sobre mi pueblo, sobre Israel; y he estado contigo en todo cuanto has andado, y delante de ti he destruido a todos tus enemigos, y te he dado nombre grande, como el nombre de los grandes que hay en la tierra ${ }^{26}$. Análogo compromiso se manifiesta, por ejemplo, en 2 Sam. 5:10: «Y David iba adelantándose y engrandeciéndose, y Yavé, Dios de los ejércitos, estaba con él». De nuevo, podría argüirse que es solo Dios quien actúa mediante su asistencia al elegido ${ }^{27}$.

Cabe detenerse ahora en el parlamento de David en el que se concreta su súplica de perdón, culmen teológico de la obra de Godínez. En estricta fidelidad al modo en que se refiere el episodio en el salmo 51, David admite haber pecado solo contra Dios, en un curioso artificioso - presente también en el salmo, en el enigmático versículo 51, 4: «Contra ti, contra ti solo he pecado. $\mathrm{Y}$ he hecho lo malo delante de tus ojos»-, a través del cual parece querer evitarse que David sienta que ha pecado contra Urías, ya que, en el judaísmo, los pecados contra los hombres deben ser perdonados por estos, pues estos son quienes sufren la afrenta -esta es la razón por la que Urías se presenta en forma de fantasma ante Bersabé, para perdonarla, pues Dios no podría hacerlo por sí mismo, hasta tanto el ofensor no haya recibido el perdón de la víctima ${ }^{28}$. Discurrir de modo expreso sobre tal imposibilidad no sería tan solo admitir que David no obtendría el perdón, sino desvelar una debilidad en Dios que podría haber propiciado, de nuevo, las sospechas de la Inquisición. Godínez aparece, pues, resuelto a apelar a la infinita capacidad de redención divina, ya que infinita es su promesa, y recalca que siendo David rey, no le incumbe suplicar el perdón de otro hombre. Es destacable que, en el cristianismo, a diferencia de lo que acabamos de exponer, el poder de Dios para perdonar incluso las ofensas cometidas contra otros hombres es un atributo infinito y que también delegados y ministros de Dios pueden, como es sabido, ejercerlo.

Es importante, con el fin de dilucidar la filiación hebrea de la naturaleza del perdón que David suplica, señalar cómo el monarca insiste en su arrepentimiento y que este primer paso es requisito para que la misericordia divina se dé:

Gran Dios, en esta ocasión

que te he menester propicio,

26. 2 Sam 7: 8-9.

27. Cf. también, con respecto a la predilección divina por David en el libro primero de Samuel, Benjamin J. M. Johnson, 2012.

28. Cf. III, vs. 2651-2706. 


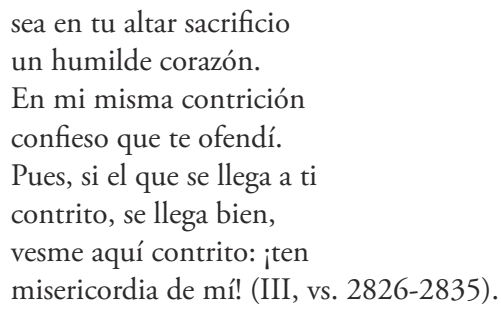

La contrición, así pues, como condición previa para que tenga lugar el perdón, que en modo alguno cabe que sea inmerecido, en el sentido de que dependa de una gratuidad de la clemencia por parte de un Dios que podría, si así lo decidiese, otorgarlo sin el previo sincero arrepentimiento del ofensor, como así ocurre en el cristianismo. Tal como Oxtoby lo expone: "Un Dios justo requiere rectitud por parte del hombre" (Oxtoby 1949: 418). En este sentido, es "el espíritu quebrantado, (un) corazón contrito y humillado"29 lo que se exige, en consonancia con lo que el entero salmo 51 estipula, pero no sacrificios ${ }^{30}$. Se trata, pues, de un perdón condicionado a que el hombre, previamente a que este se conceda, muestre que comprende de nuevo el sentido de la alianza y retorne a la lealtad que esta comporta. Así, la maldad que se refiere en Sal 51: 3: "He aquí, en maldad he sido formado, y en pecado me concibió mi madre", no remite a un estigma que retrotraiga a un pecado primigenio, sino solo a que se está sujeto, como humano, a la confusión moral que comporta, si esto sucede, el olvido de la alianza. Y el arrepentimiento consiste en un cambio en el propio corazón que pugna por retornar a sí mismo. Aunque ocurrida esta transformación, la contrapartida que obliga a Dios a perdonar es igualmente perentoria (Danglish 1962: 82-100).

Prosigue David:

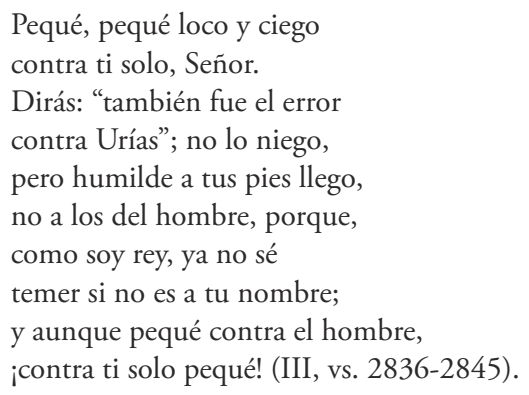

El ahínco de David por tratar de eludir la responsabilidad frente al hombre, que le lleva a aducir su privilegio de rey, le induce asimismo a proclamar que solo le teme a Dios. Su defensa podría sospecharse como una argucia, porque sabe que, si admitiera que el pecado había sido contra Urías, Dios no podría perdonarlo y que en el judaísmo no cabe el recurso a la infinita clemencia divina. 
Que pueda sospecharse como una intencionada finta el que únicamente se implore el perdón divino resulta notorio por las siguientes líneas:

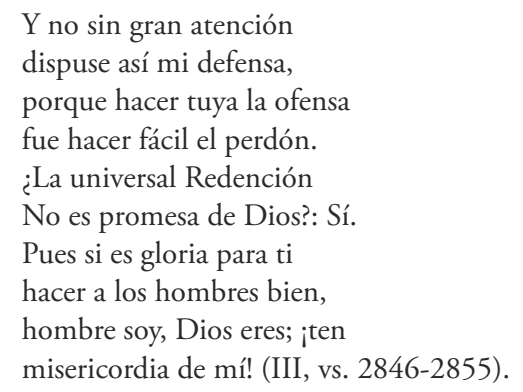

Sin embargo, quien suplica sabe que solo el amor de Dios hacia Israel es un hecho incontrovertible e incesante que conduce a dirigir hacia Él, de modo intuitivo, la súplica. Y aunque pudiera parecer que David apela a una gratuita redención, lo que hace el rey, de manera velada, es instar a Dios a recordar que no puede no perdonar a aquel con quien ha establecido su alianza y que sinceramente se arrepiente. De nuevo se pone en entredicho la omnipotencia divina, que nunca es afirmada como atributo en el Antiguo Testamento, en el que se describe un Dios imperfecto, necesitado de los hombres a los que crea y de que estos cumplan su parte de la alianza para Aquel alcanzar, a través de dicho cumplimiento, la perfección. La misericordia solicitada parece serle casi exigida porque se sabe que la actitud de Dios para con Israel permite confiar en que tal requerimiento es posible (Lapsley, 2003: 360), como leemos en Dt 7: 7-8: «No por ser vosotros más que todos los pueblos os ha querido Yavé y os ha escogido, pues vosotros erais el más insignificante de todos los pueblos; sino por cuanto Yavé os amó, y quiso guardar el juramento que juró a vuestros padres».

En los versos que siguen, en los que el monarca insiste además en que su contrición le ha convertido en otro distinto del que pecó, culmina el sentido por el que se retorna a la instancia primera, aquella en la que se estableció la mutua lealtad con Dios:

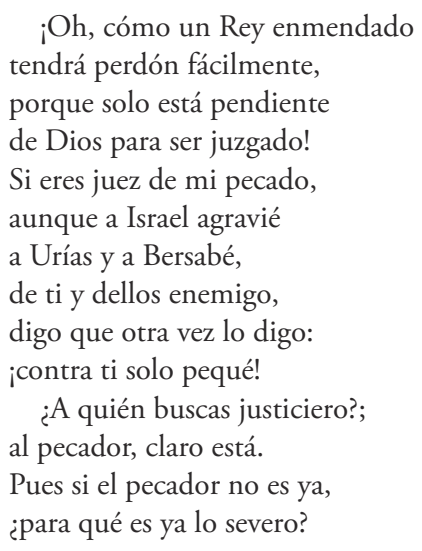




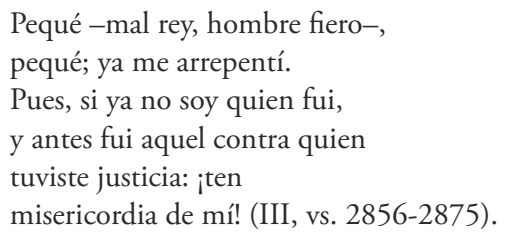

David parece instar a Dios a recordar que, ya no estando el pecador -pues quien había olvidado el pacto, acaba de retornar a él-, no cabe sino otorgar el perdón, que el arrepentimiento concita en función del berit, el compromiso de mutua lealtad. Pero sobre todo, le recuerda que ya no es el que fue, aquel "contra quien tuviste justicia", esto es, merecedor de ser juzgado por sus acciones con rigor divino.

Habrá que retornar a la fidelidad y consideración mutuas asentadas sobre el berit, pues el arrepentimiento lo es de haberse alejado uno de ser aquel que vivía en el seno de la alianza y tiene el sentido de regreso a esta o regreso a sí mismo, a uno mismo. Por lo demás, los profetas mostraron cierto despecho por quienes se abocaban a enfatizar la transformación espiritual a través de manifestaciones externas, ajenas a la regeneración del corazón. Así, Os 14 vindica la súplica íntima: «Llevad con vosotros palabras de súplica, y volved a Yavé, y decidle: Quita toda iniquidad, y acepta el bien, y te ofreceremos la ofrenda de nuestros labios», como asimismo Ex 18:31: «Echad de vosotros todas vuestras transgresiones con que habéis pecado, y haceos un corazón nuevo y un espíritu nuevo». También Jer 24:7: «Y les daré corazón para que me conozcan que yo soy Yavé». Samain (1949: 29) vinculaba, en dicho sentido, el salmo 51 con pasajes de los dos grandes profetas del exilio: Jeremías, para quien la alianza se sostiene, en efecto, no sobre leyes externas, sino sobre la regeneración interior, e Isaías, en quien se da una suerte de acción perenne del sostén divino, que asiste en lo más íntimo al corazón humano. Cabe comparar, asimismo, aquel salmo, sobre todo Sal 51: 10: «Crea en mí, oh Dios, un corazón limpio», y Sal 51: 17: «Los sacrificios de Dios son el espíritu quebrantado", con pasajes de otros salmos. La bondad divina que sustenta la vuelta a sí mismo del pecador que se arrepiente se halla también en Sal 40:17: «Aunque afligido yo y necesitado, Yavé pensará en mí», o Sal 130: 3: «Espera Israel a Yavé, porque en Yavé hay misericordia, y abundante redención con Él». Se implora, por su parte, el perdón -aunque con cierto deje de exigencia- en Sal 25: 11: «Por amor de tu nombre, oh Yavé, perdonarás mi pecado, que es grande», y en Sal 130: 4: «Pero en ti hay perdón, para que seas reverenciado", y se reclama la ayuda divina para evitar el pecado en Sal 6:3: «Vuélvete, oh Yavé, libra mi alma; sálvame por tu misericordia», o en Sal 38:22: "Apresúrate a ayudarme, oh Señor, mi salvación», y Sal 69:29: "Mas a mí, afligido y miserable, tu salvación, oh Dios, me ponga en alto». Son solo algunos de los numerosos versículos de los salmos que abundan en la noción del perdón instituido sobre la alianza davídica.

De nuevo, en los últimos versos, se insiste en la certeza del perdón que este retorno comporta: 


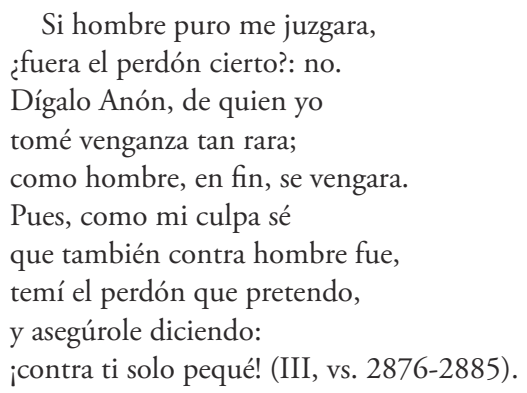

Godínez concreta el parlamento sobre la naturaleza condicionada del perdón, de un modo acorde a cómo se relata el episodio en el pasaje bíblico, y hace de él un instrumento para la vindicación de una concepción del mismo opuesta a la cristiana. David, en la Escritura, y pese a reconocer que ha pecado contra Dios, solo lo hace tras haberle reprochado Natán su conducta a través del símil de los dos hombres, el rico, que da a su huésped la única oveja que el segundo, pobre, posee, en lugar de obsequiarle con una de las muchas de las que él mismo es dueño y cuya actitud el monarca condena para acusarle Natán acto seguido de ser David aquel hombre y desvelarle que Dios, en consecuencia, no apartará su espada de su casa, por haberle el monarca menospreciado, tomando como esposa a Bersabé (Simon, 1967).

También en otros pasajes de los salmos, y no solo en el 51, se afirma el vínculo entre Dios y los hombres que ejemplifica el berit. Así, por ejemplo, el siguiente: «Mi pecado te declaré, y no encubrí mi iniquidad. Dije: Confesaré mis transgresiones a Yavé; Y tú perdonaste la maldad de mi pecado. Por esto orará a ti todo santo en el tiempo en que puedas ser hallado» ${ }^{31}$. Un hésed especial se establece, por lo demás, entre Yavé y la casa de David, y este se describe en pasajes de libros diferentes, como 1 R 8, 2332, Neh. 1, 533, Dn. 9, $4^{34}$ y otros. $\mathrm{Ni}$ siquiera cuando la alianza se quiebra podrá revocarse el hésed, pues este llega a ser, de modo casi paradójico, una característica inherente a Dios, que lo define y que se concreta como un modo específico de actuar. Se trata del fundamento de las acciones dirigidas al pueblo elegido. El vínculo entre hésed y la raíz rhm, que mantiene un cierto significado de compasión, comporta que la lealtad conlleve, asimismo, un contenido emocional. En este sentido, Jacob ${ }^{35}$ arguye que la inicial connotación de la palabra 'hésed' no tiene equivalente en las lenguas modernas y que los estudios etimológicos son de escasa ayuda, poco más allá de consignar que el significado primigenio del término era "fuerza".

31. Sal. 32, 5-6.

32. «dijo: Yavé Dios de Israel, no hay Dios como tú, ni arriba en los cielos ni abajo en la tierra, que guardas el pacto y la misericordia a tus siervos, los que andan delante de ti con todo su corazón».

33. «Y dije: Te ruego, oh Yavé, Dios de los cielos, fuerte, grande y temible, que guarda el pacto y la misericordia a los que le aman y guardan sus mandamientos».

34. "Y oré a Yavé mi Dios e hice confesión diciendo: Ahora, Señor, Dios grande, digno de ser temido, que guardas el pacto y la misericordia con los que te aman y guardan tus mandamientos».

35. Jacob Edmond, 1955. 
En Oseas se profundiza en su significado, que implica, además de la alianza, la noción de tal fuerza, la que impele a Dios a entrar en relación con su pueblo, pero cuyo significado se expande hasta abarcar toda la creación.

El sentimiento, por parte de los israelitas, de que Dios se ha comprometido a auxiliarles, halla también constatación en Sal. 132: 11-12, donde leemos: «En verdad juró Yavé a David, y no se retractará de ello: De tu descendencia pondré sobre tu trono. Si tus hijos guardaren mi pacto, y mi testimonio que yo les enseñaré, sus hijos también se sentarán sobre tu trono para siempre». Del mismo modo, el David de Godínez indica, en su súplica a Dios, que apela a su compromiso de perdonar, antes que a un poder incondicionado de hacerlo, en línea con Sal. 36, 5: «Yavé....tu fidelidad alcanza hasta las nubes»" ${ }^{36}$. Ante tales evidencias textuales, no cabe sino concluir, nos parece, que las características del perdón obtenido por David obedecen a la consideración judía acerca de los requisitos para el otorgamiento del mismo, por oposición a la infinita e incondicional clemencia que el Dios cristiano concede gratuitamente.

\section{Bibliografía}

Anibal Claude E., «Voces del cielo: A Note on Mira de Amescua», The Romanic Review 16, 1925, 57-70.

Anibal Claude E., «Another note on the Voces del cielo», The Romanic Review 18, 1927, 246-252.

Asensio Félix, «Un aspecto de la asistencia divina en el Antiguo Testamento», Sal Terrae 32, 1944, 689-697.

Asensio Félix, «Un aspecto de la asistencia divina en el Antiguo Testamento», Sal Terrae 33, 1945, 23-26.

Asensio Félix, Misericordia et Veritas, el Hesed y Emet divinos, su influjo religioso-social en la historia de Israel. Roma, Apud Aedes Universitatis Gregorianae, 1949.

Beltrán Miquel, «La cuestión de la asistencia divina en Las lágrimas de David, de Felipe Godínez», en Tiempo e historia en el teatro del Siglo de Oro. Actas selectas del XVI Congreso Internacional de la AITENSO, ed. de Isabelle Rouane Soupault y Philippe Meunier. Aix-en-Provence. Presses Universitaires de Provence, 2015, 126134.

Bodner Keith, The Rebellion of Absalon. Routledge. Taylor \& Francis, 2014.

Bolaños Donoso Piedad, La obra dramática de Felipe Godinez (Trayectoria de un dramaturgo marginado). Sevilla, Excma. Diputación Provincial de Sevilla, 1983.

Calderón de la Barca Pedro, Los cabellos de Absalón, ed. de Evangelina RodríguezCuadros. Madrid, Espasa-Calpe, 1989.

36. La reciprocidad del compromiso se hace tangible en los reproches que Yavé dirige, en ocasiones, contra su olvidadizo pueblo. Así en Os. 6, 4: «QQué haré a ti, Efraín? ¿Qué haré a ti, oh Judá? La piedad vuestra es como nube de la mañana, y como el rocío de la madrugada, que se desvanece». 
Dalglish Edward Russell, Psalm Fifty-One in the Light of Ancient Near Eastern Patternism. Leiden, Brill, 1962.

Díaz Jimeno Felipe, Hado y fortuna en la España del siglo XVI. Madrid, Fundación Universitaria Española, 1987.

Dixon Victor F., «El santo rey David y Los cabellos de Absalón», en Hacia Calderón. Tercer Coloquio Anglo-Germano, ed. de Hans Flasche. Berlín. Walter de Gruyter, 1976, 84-98.

Dixon Victor F., "Prediction and its Dramatic Function in Los cabellos de Absalón», Bulletin of Hispanic Studies 6, 1984, 301-316.

Edmond Jacob, Théologie de l'Ancien Testament. Neuchatel, Delachaux et Nietslé, 1955.

Edwards Gwynne, "Introduction» to Pedro Calderón de la Barca's Los cabellos de Absalón, ed. de Gwynne Edwards. Nueva York, Pergamon Press, 1973, 1-33.

Edwards Gwynne, The Prison and the Labyrinth. Studies in Calderonian Tragedy. Cardiff, University of Wales Press, 1978.

Fine Ruth, "Siendo yo hebrea, Señor": Una lectura de "La reina Ester" de Felipe Godínez en clave conversa", Compostella aurea, actas del VIII Congreso de la Asociación Internacional del Siglo de Oro (AISO), Santiago de Compostola, 7-11 de julio de 2008, 652-659.

Fine Ruth, «Los rostros de Ester-Tres versiones dramáticas auriseculares del libro de Ester: La hermosa Ester de Lope de Vega, La reina Ester de Godínez y La gran sultana de Cervantes", Hispania Judaica Bulletin 7, 2010, 233-259.

Gluck Nelson, Hesed in the Bible. Traducido del alemán por Alfred Gottschalk. Wipf \& Stock. Oregón, Eugene, 2011. El original, en alemán, fue defendido como tesis doctoral en 1927.

Godínez Felipe, Las lágrimas de David, ed. de Edward V. Coughlin y Juan O. Valencia, Valencia, Albatros Hispanófila, 1986.

Godínez Felipe, Las lágrimas de David, ed. de Germán Vega García-Luengos, Canon 60 del TC/12 (Patrimonio del teatro clásico español. Textos e instrumentos de investigación), 2013, http://tc12.uv.es/index.php/produccion-cientifica/ediciondel-patrimonio-teatral/canon-60.

Gowan Donald, Theology in Exodus. Biblical Theology in the Form of a Commentary. Louisville KY, Westminster, John Knox Press, 1994.

Herskovits Andrew, The Positive Image of the Jew in the "Comedia". Nueva York, Peter Lang, 2005.

Herskovits Andrew, «The Judaization of Christianity in Felipe Godínez’s Ester Plays», Bulletin of the Comediantes 60, 2008, 51-70.

Hoftijzer Joab J., «David and the Tekoite Woman», Vetus Testamentum 20, 1970, 419444.

Huttar Charles A., «Frail Grass and Firm Tree: David as a Model of Repentance in the Middle Ages and Early Renaissance», ed. de Raymond-Jean Frontain y Jan Wokcik, West Lafayette, Indiana, Purdue University Press, 1980, 38-55.

Janzen David, «The Condemnation of David's “Taking” in 2 Samuel 12: 1-14», Journal of Biblical Literature 131, 2012, 209-220.

Johnson Benjamin J. M., "The Heart of Yhvh's Chosen One in 1 Samuel», Journal of Biblical Literature 131, 2012, 455-466. 
Lapsley, Jacqueline E., "Feeling Our Way: Love for God in Deuteronomy», Catholic Biblical Quarterly 65, 2003, 350-369.

Lofthouse W. F., "Hen and Hesed in the Old Testament", Zeitschrift für die Alttestamentiliche Wissenschaft 51, 1933, 29-35.

Lope de Vega y Carpio Félix, David perseguido y montes de Gelboé. Red ediciones S. L., 2012.

Marcus David, «David the Deceiver and David the Dupe», Prooftexts 6, 1986, 163171.

McCarthy D. F., «II Samuel 7 and the Structure of the Deuteronomistic History», Journal of Biblical Literature 84, 1965, 131-138.

Menéndez Onrubia Carmen, "Hacia la biografía de un iluminado judío: Felipe Godínez (1585-1659)», Segismundo 25-26, 1982, 1-42.

Mira de Amescua Antonio, El arpa de David, ed. de G. Vern y James T. Williamsen, en http://www.coh.arizona.edu/spanish/comedia/mira/arpdav.html (accesible desde el 2 de Agosto de 2003).

Muñoz León Domingo, Dios-Palabra: Memrá en los Targumim del Pentateuco. Granada, Institución San Jerónimo, 1974.

Muñoz León Domingo, Gloria de la Shekina en los Targumim del Pentateuco. Madrid, Instituto Francisco Suárez, Consejo Superior de Investigaciones Científicas, 1977.

Muñoz León Domingo, Palabra y gloria: excursus en la Biblia y en la literatura intertestamentaria. Madrid, Instituto Francisco Suárez, Consejo Superior de Investigaciones Científicas, 1983.

Oxtoby Gurdon Corning, "Conscience and Confession: A Study of the Fifty-First Psalm», Interpretation 3, 1949, 415-426.

Park Song-Mi Suzie, «The Frustration of Wisdom: Wisdom, Counsel, and Divine Will in 2 Samuel 17, 1:23", Journal of Biblical Literature 128, 2009, 453-467.

Parks Ted, "Religion and Politics in Felipe Godínez's El divino Isaac», Bulletin of the Comediantes 42, 1997, 55-66.

Sakenfeld Katharine Doob, The Meaning of Hesed in the Hebrew Bible. Missoula, Scholars Press, 1978.

Sakenfeld Katharine Doob, Loyalty in Biblical Perspective. Faithfulness in Action. Philadelphia, Fortress Press, 1985.

Sanz Giménez-Rico Enrique, Cercanía del Dios distante: Imagen de Dios en el libro del Exodo. Madrid, Universidad Pontificia Comillas, 2002.

Shergold N. D. y Varey J. E., "Some Palace Performances of Seventeenth-Century Plays", Bulletin of Spanish Studies 40, 1963, 212-244.

Simon Uriel, «The Poor Man's Ewe-Land. An Example of a Juridical Parable», Biblica 48, 1967, 207-242.

Sloman Albert E., The Dramatic Craftsmanship of Calderón, His Use of Earlier Plays, Manchester, Manchester University Press, 1961.

Smith Richard G., The Fate of Justice and Righteousness during David's Reign. Narrative Ethics and Rereading the Court History according to 2 Samuel 8:15-20:26. Bloomsbury, T \& T Clark International, 2009.

Sorg Dom Rembert, Hesed and Hasid in the Psalms. St. Louis, Pio Decimo Press, 1953. 
Valencia Juan O., Pathos y tabú en el teatro bíblico del Siglo de Oro. Madrid, Ediciones y distribuciones Isla, 1977.

Vega García-Luengos Germán, Problemas de un dramaturgo del Siglo de Oro. Estudios sobre Felipe Godinez. Con dos comedias inéditas. Valladolid, Secretariado de Publicaciones de la Universidad de Valladolid, 1986.

Vega García-Luengos Germán, "Una edición crítica para Las lágrimas de David, la comedia más difundida de Felipe Godínez», en La edición de textos. Actas del I Congreso Internacional de Hispanistas del Siglo de Oro (Madrid, 1987). Londres, Támesis Books, 1989, 483-491.

Wharton James A., "A Plausible Tale: Story and Theology in II Samuel 9-20, 1 Kings 1-2», Interpretation 35, 1981, 341-354. 